\title{
ARTICLE
}

\section{A Defense of Intrapersonal Belief Permissivism}

\author{
Elizabeth Jackson* \\ Australian National University and Ryerson University \\ ${ }^{*}$ Corresponding author. Email: lizjackson111@gmail.com
}

(Received 22 May 2018; revised 7 March 2019; accepted 21 May 2019; first published online 11 July 2019)

\begin{abstract}
Permissivism is the view that there are evidential situations that rationally permit more than one attitude toward a proposition. In this paper, I argue for Intrapersonal Belief Permissivism (IaBP): that there are evidential situations in which a single agent can rationally adopt more than one belief-attitude toward a proposition. I give two positive arguments for IaBP; the first involves epistemic supererogation and the second involves doubt. Then, I show how these arguments give intrapersonal permissivists a distinct response to the toggling objection. I conclude that IaBP is a view that philosophers should take seriously.
\end{abstract}

Keywords: Doubt; Epistemic Supererogation; Evidence; Permissivism; Pragmatic Encroachment; Rationality; Salience; Uniqueness

\section{Introduction}

\subsection{Permissivism and uniqueness}

How stringent is rationality? Is there ever slack between a body of evidence and what one can rationally conclude, given that evidence? Proponents of uniqueness say no; uniqueness is the view that, for every body of evidence and proposition $p$, there is one unique rational doxastic attitude someone with that evidence can take toward p. ${ }^{1}$ Permissivists, on the other hand, maintain that sometimes, there is slack between a body of evidence and what it is rational to conclude; a body of evidence alone does not always determine a particular rational attitude one must take toward a proposition. ${ }^{2}$ Note first that uniqueness is a universal claim and permissivism is an existential claim; permissivists do not maintain that every body of evidence is permissive, but merely that some are. For instance, the evidence that most of us possess rationally requires believing that $1+1=2$; this is consistent with the permissivism.

\footnotetext{
${ }^{1}$ Defenses of uniqueness include Feldman (2000, 2006, 2007), White (2005, 2007, 2013), Christensen (2007), Matheson (2011), Hedden (2015a, 2015b), Greco and Hedden (2016), Dogramaci and Horowitz (2016), Schultheis (2018), Horowitz (2019), Stapleford (Forthcoming).

${ }^{2}$ Defenses of permissivism include Rosen (2001), Douven (2009), Titelbaum (2010), Ballantyne and Coffman (2011), Brueckner and Bundy (2012), Decker (2012), Rosa (2012), Kelly (2013), Meacham (2014, 2019), Schoenfield (2014, Forthcoming), Peels and Booth (2014), Raleigh (2015, 2017), Kopec (2015), Sharadin (2015), Podgorski (2016), Willard-Kyle (2017), Drake (2017), Jung (2017), Daoust (2017), Simpson (2017), Titelbaum and Kopec (2019), Dahlback (Forthcoming), Weisberg (Forthcoming), Thorstad (Forthcoming).

(C) Cambridge University Press 2019
} 
There are many ways to be a permissivist; here, I will focus on three main distinctions. ${ }^{3}$ The first involves the attitudes in question.

Credal Permissivism: there are evidential situations that rationally permit more than one credence toward a proposition.

Belief Permissivism: there are evidential situations that rationally permit more than one belief-attitude toward a proposition.

Various combinations of Belief Permissivism and Credal Permissivism are possible, depending on one's views on the relationship between belief and credence. ${ }^{4}$ For example, one might hold that a body of evidence requires belief that $\mathrm{p}$, but permits any credence in $\mathrm{p}$ between 0.8 and 0.9. This sort of view entails Credal Permissivism but not Belief Permissivism. There are also views that entail Belief Permissivism but not Credal Permissivism. For example, if the practical encroaches on rational belief but not rational credence, and instead, rational credence tightly tracks the evidence, it might be that a body of evidence allows more than one rational belief-attitude (depending on the stakes) but requires a particular credence. ${ }^{5}$

Second, there are two types of Belief Permissivism. Assuming there are primarily three belief-attitudes one can take toward a proposition $\mathrm{p}$ - believing $\mathrm{p}$, withholding belief on $\mathrm{p}$, and disbelieving $\mathrm{p}$ - we can distinguish between the following:

Moderate Permissivism: there are evidential situations that rationally permit two belief-attitudes toward a proposition (where withholding is always one of the permitted attitudes).

Extreme Permissivism: there are evidential situations that rationally permit all three belief-attitudes toward a proposition. ${ }^{6}$

Extreme Permissivism entails Moderate Permissivism but not vice versa, so Extreme Permissivism is the stronger view. A final distinction is as follows:

Interpersonal Permissivism (IeP): there are evidential situations in which two (or more) agents can rationally adopt more than one doxastic attitude toward a proposition.

Intrapersonal Permissivism (IaP): there are evidential situations in which a single agent can rationally adopt more than one doxastic attitude toward a proposition. ${ }^{7}$

Many permissivists have argued for IeP but not IaP; they endorse a view that is permissive across individuals, but impermissive with respect to the doxastic options open to a single individual. ${ }^{8}$ For example, Schoenfield (2014) has argued for IeP on the basis of

\footnotetext{
${ }^{3}$ See Meacham (2014), Kopec and Titelbaum (2016), and Titelbaum and Kopec (2019) for helpful distinctions between different types of permissivism.

${ }^{4}$ For a more extensive discussion of this point, see Jackson (Forthcoming $a$ ).

${ }^{5}$ Thanks to Michael Hatcher. I discuss the relationship between pragmatic encroachment and permissivism more extensively in Section 3.

${ }^{6}$ This distinction is found in White (2005); however, White characterizes Credal Permissivism as a type of Moderate Permissivism. See also Horowitz (2014).

${ }^{7}$ This distinction is found in Kelly (2013), Meacham (2014: 1190) and Titelbaum and Kopec (2019).

${ }^{8}$ See Kelly (2013: 304). Nonetheless, it is not clear that Intrapersonal Permissivism is logically stronger than Interpersonal Permissivism. See Meacham (2014).
} 
individuals' differing epistemic standards; others interested in peer disagreement have suggested that if evidence is interpersonally permissive, peers could disagree without compromising rationality. ${ }^{9}$ However, there have been almost no defenses of IaP in the literature. This paper is an attempt to fulfill that lacuna, and argue not only that permissivism is true, but that a strong version of permissivism is true.

More precisely, I will defend:

Intrapersonal Belief Permissivism (IaBP): there are evidential situations in which a single agent can rationally adopt more than one belief-attitude toward a proposition. ${ }^{10}$

This is a stronger view than most permissivists in the literature have endorsed, and few have offered explicit arguments for IaBP. ${ }^{11}$ Some of my arguments will be for Extreme Permissivism (three belief-attitudes are permitted), and others will be for Moderate Permissivism (two belief-attitudes are permitted). I am more concerned with defending IaBP than defending an extreme version of IaBP, so I will be happy if the reader leaves sympathetic to merely a moderate version.

The paper is structured as follows. I close this section by clarifying my understanding of two notions central to IaBP: the notion of rationality and the notion of evidence. In Section 2, I give the first argument for IaBP; I argue that cases of epistemic supererogation imply IaBP is true. In Section 3, I give a second argument for IaBP: that the possibility of certain kinds of rational doubting entails IaBP. In Section 4, I show how the version of IaBP defended in this paper gives the intrapersonal permissivist a novel response to the toggling objection. I conclude in Section 5.

\subsection{Rationality and evidence}

In standard formulations of permissivism and uniqueness (including the above), two notions are especially salient: the notion of rationality and the notion of evidence. Many in the permissivism/uniqueness literature do not define or explicate these concepts, but rather treat them as primitives. However, this practice may mean that defenders of permissivism and uniqueness are talking past each other: permissivists relying on a narrow understanding of evidence and a lower bar for rationality, and impermissivists relying on a broad understanding of evidence and a high bar for rationality. Thus, it is crucial to clarify these notions so each side is not unhelpfully talking past each other. ${ }^{12}$

In this paper, I adopt a moderate understanding of both rationality and evidence. That is, a notion of evidence that is neither overly narrow nor overly broad, and a bar for rationality that is high but not maximally high. This seems most fair to each side, because going too far in one direction both stacks the deck in a particular view's favor, but also makes that view less interesting. For example, if we adopt a very high bar for rationality (e.g. rationality as fully idealized rationality) then uniqueness might be true, but it is a less controversial thesis. ${ }^{13}$ A similar worry would apply to a version of permissivism that invokes a low bar for rationality. Before proceeding, I say a little more about what I have in mind by "evidence" and "rationality."

\footnotetext{
${ }^{9}$ Defenses of IeP include Douven (2009), Kelly (2013), Meacham (2014), Schoenfield (2014).

${ }^{10}$ Thanks to Lizzie Fricker.

${ }^{11}$ One exception involves the case of self-fulfilling beliefs; see Kopec $(2015)$, Raleigh $(2015,2017)$, Sharadin (2015) and Drake (2017). For an impermissivist response to these cases, see Greco and Hedden (2016: 371).

${ }^{12}$ For an example of an attempt to avoid this, see Schoenfield (Forthcoming).

${ }^{13}$ Although fully idealized rationality may not always entail uniqueness; Bayesian rationality, for example, is in some sense idealized but is (interpersonally) permissive. Thanks to Ru Ye.
} 
The notion of evidence I invoke is a set of propositions that includes an agent's total evidence. Generally, I'm thinking of evidence as states like an agent's beliefs or knowledge, although I want to remain neutral on debates such as whether $\mathrm{E}=\mathrm{K}$ (that is, whether your evidence is identical to what you know). ${ }^{14}$ The notion of evidence I adopt is broad in the sense that it includes both an agent's occurrent and non-occurrent states. $^{15}$

The notion of rationality I am concerned with is epistemic, as opposed to e.g. practical or all-things-considered rationality. Further, as noted above, the notion of rationality I am concerned with is not fully idealized rationality, that is, it is applicable to agents like us. ${ }^{16}$ I mentioned reasons for adopting a notion like this above, but here is another. One of the reasons people initially became concerned with the permissivism/uniqueness debate is because they wanted to know what they ought to believe, for example, in response to peer disagreement. ${ }^{17}$ However, if rationality speaks to what we ought to believe, its norms must, at least to an extent, inform the beliefforming processes of actual agents. And a norm cannot be informative in this way unless it applies to agents that are at least approximately similar to human beings. Further, plausibly, the violation of epistemic norms provides grounds for criticizing or blaming people for their beliefs. This is another reason fully idealized epistemic norms appear to be inappropriate; it seems unfair to blame people for failing to meet an unattainable standard. ${ }^{18}$ Thus, if the notion of rationality at play in the permissivism/uniqueness debate is fully idealized rationality, then it is unclear that this debate would bear on other debates, such as how we should alter our beliefs in response to disagreement, in any interesting way.

I have several thoughts for a defender of uniqueness who rejects my arguments for IaBP in virtue of rejecting my understanding of either of these notions. First, I have tried my best to rely on moderate versions of each concept, neither stacking the deck in favor of permissivism or uniqueness, nor making either thesis trivial or uninteresting. The counterexamples to uniqueness below rely on moderate and intuitive versions of each. Second, if an impermissivist is still unsatisfied with my arguments in virtue of a disagreement about evidence or about rationality, I nonetheless think my paper makes a contribution. It points those who are sympathetic to my understanding of evidence and rationality to cases that support permissivism - cases that have largely been overlooked in the literature.

This isn't to say defenders of uniqueness cannot resist these counterexamples by raising the bar for rationality or broadening the notion of evidence at play. However, the more they resist counterexamples by using this strategy, the less interesting (and more trivial) uniqueness becomes. These debates best proceed by agreeing on moderate versions of these notions and seeing what arguments can be made from there. In what follows, I attempt to do just that.

\footnotetext{
${ }^{14}$ See Williamson (2000: Ch. 9).

${ }^{15}$ Following Podgorski (2016).

${ }^{16} \mathrm{An}$ example of rationality that is too idealized to apply to human agents is the Bayesian probabilism norm. This norm requires one to conform one's credences to the Kolmogorov axioms of probability, requiring agents to adopt credence 1 in every logical (or necessary) truth. However, this norm is not applicable to agents like us because (i) we cannot know, of many propositions (e.g. unproven mathematical theorems like Goldbach's conjecture), whether they are logical truths, and (ii) many logical truths are too complex for us to grasp.

${ }^{17}$ See Douven (2009), Ballantyne and Coffman (2011, 2012), Lee (2013), Levinstein (2015), Christensen (2016), Jung (2016) and Willard-Kyle (2017).

${ }^{18}$ Thanks to an anonymous referee.
} 


\section{Epistemic supererogation}

My first positive argument for IaBP involves epistemic supererogation. ${ }^{19}$ Supererogatory acts, a familiar category in ethics, are those that are morally good but not morally required, as they go "above and beyond" one's moral obligations. Intuitive examples of morally supererogatory actions include running into a burning building to save a trapped dog or selling most of one's possessions to give the money to charity.

Several have argued that moral supererogation has a counterpart in the epistemic domain. ${ }^{20}$ Here is a rough idea of how supererogation might apply to the epistemic:

Epistemic supererogation: states or actions that are epistemically good but not epistemically required.

There is a distinction between two kinds of epistemic supererogation that is significant for our purposes: epistemically supererogatory acts that involve changes to one's evidence, and those that don't. Examples that involve changes to one's evidence that are mentioned in Hedberg (2014) are double checking your ATM pin even though you haven't forgotten it in the past (3628) or reading 12 articles rather than 10 on the nominalist/realist debate before forming an opinion (3631). Here, I will set cases like those aside and focus on epistemic supererogation that does not involve changes to one's evidence. My basic argument in this section is as follows:

2.1 There are cases of epistemic supererogation that do not involve changes to one's evidence.

2.2 If there are cases of epistemic supererogation that do not involve changes to one's evidence, then IaBP is true.

2.3 Therefore, IaBP is true.

To defend (2.1), I provide several examples. Then, in defense of (2.2), I show how these examples give us a reason to accept IaBP.

Before discussing the support for (2.1), note that many epistemologists, including Feldman (2000), Kelly (2002: fn 30) and Berker (2018) argue that evidence-altering actions such as evidence gathering and inquiry are always or almost always governed by prudential norms, rather than epistemic ones; there are no epistemic reasons for action. On this view, there is a sense in which evidence gathering can be supererogatory; it will just not count as epistemic supererogation. Thus, if they are correct, then the clearest cases of epistemic supererogation are not going to be cases of actions that change one's evidence.

There are several examples in the literature that support (2.1). One example, mentioned by Tidman (1996) and Hedberg (2014), involves critically reflecting on one's evidence. Tidman (1996: 270) notes, "We do not have the duty to critically reflect upon the vast number of ordinary beliefs we pick up throughout the day without even noticing, e.g. beliefs about breakfast or passers-by ..." He argues that, even if these low-stakes, everyday beliefs would change upon reflection, that does not mean one has an epistemic duty to reflect on them; maybe right after forming the beliefs, one is distracted by an automobile accident and never considers the belief again. Has one violated an epistemic

\footnotetext{
${ }^{19}$ Podgorski (2016) also supports permissivism using supererogation cases, but our arguments are importantly different; my argument is more general and doesn't rely on Podgorski's process framework. Thanks to an anonymous referee. Li (2019) also connects permissivism and supererogation, but he argues for the opposite entailment: he argues that permissivists ought to accept epistemic supererogation, whereas I argue that epistemic supererogation entails permissivism.

${ }^{20}$ See Bernstein (1986), Tidman (1996), Hedberg (2014) and McElwee (2016).
} 
duty? No; it is neither realistic nor reasonable to require that one always critically reflect on one's ordinary beliefs. ${ }^{21}$ If critical reflection on everyday beliefs is epistemically good but not required, this supports the idea that this kind of reflection is supererogatory.

A second example is from Igor Douven (2009). He gives a case where you are a juror on a trial, deliberating about whether Smith is guilty. You are trying to figure out what best explains the evidence, and you conclude that Smith is guilty by the inference to the best explanation (IBE). Then, in a sudden flash of insight, you see that your evidence is actually better explained by the hypothesis that Jones, Smith's butler, committed the crime. ${ }^{22}$ However, seeing that the evidence better explains this latter hypothesis is not required by rationality, as rationality does not require brilliant insights; you could have rationally believed that Smith was guilty on the basis of the same evidence. In this, having this insight is epistemically supererogatory. This example generalizes to many other cases of IBE. ${ }^{23}$

An objection to (2.1) is that the agents in these cases obtain new evidence. For example, once you realize Jones's guilt better explains your evidence, a different attitude might be rational for you, but you have new evidence. This verdict is consistent with uniqueness. My reply is twofold. First, this conception of evidence is contrary to how those in the inference to the best explanation literature think of evidence. In this literature, there is a clear demarcation between, on the one hand, one's evidence, and on the other, the hypotheses that are live for an agent. Considering a new hypothesis is not a matter of evidence change; live hypotheses are explained by one's evidence, not a part of one's evidence. What happens when one considers a new hypothesis that wasn't previously live, as the juror in our case does? Those in the inference to the best explanation literature explain this in terms of some other change. For instance, Jon Williamson $(2004,2010)$ argues that considering a new hypothesis is a change in the language one is using. ${ }^{24}$ This objection on behalf of the impermissivist thus depends on revising much of the orthodoxy in the inference to the best explanation literature.

One might worry that there are other potential candidates for evidence change here, besides a change in which hypotheses are live for an agent or which hypotheses are best explained by one's evidence. ${ }^{25}$ However, it is hard to see exactly what these so-called evidential changes would be. Further, for (2.1) to be true, all we need is one case. And we can imagine versions of the cases above where there are no changes except (a) the consideration of the new hypothesis and (b) the realization that this hypothesis better explains your evidence. (2.1) may be true even if, in similar cases, there is, in fact, a change in evidence.

Second, there is a more general worry about expanding what one counts as evidence to respond to counterexamples to uniqueness. Titelbaum and Kopec (2016) point out that, on some notions of evidence (e.g. mentalistic ones, some versions of phenomenal conservatism, etc.), uniqueness comes out trivially true, because (i) interpersonally, two

\footnotetext{
${ }^{21}$ Tidman (1996: 270). Although I don't want to rule out that there might be epistemic duties to reflect in certain cases. For example, Stapleford $(2013,2015)$ argues that we sometimes have an imperfect epistemic duty of reflection.

${ }^{22}$ Douven (2009: 351-2). See also Carter (2017).

${ }^{23}$ One key dis-analogy between moral and epistemic supererogation is that it is possible and even commonplace to know some action is morally supererogatory and nonetheless refrain from doing it. In many situations, we know we could be doing better morally. However, this doesn't hold the epistemic domain. Once one realizes that a particular doxastic attitude is epistemically supererogatory, it is virtually impossible to refrain from adopting that attitude. Thus, while there are instructive analogies between the moral and the epistemic, the domains also come apart in key ways. Thanks to Klaas Kray.

${ }^{24}$ See Williamson (2004: Ch. 12; 2010: Ch. 9), Roche and Sober (2013). Thanks to Nevin Climenhaga.

${ }^{25}$ Thanks to an anonymous referee.
} 
agents will never or almost never share evidence and (ii) intrapersonally, almost any mental change constitutes a change in evidence. ${ }^{26}$ The easier it is for one's evidence to change, the less interesting the uniqueness thesis becomes; at some point, if we keep expanding our notion of what counts as evidence, uniqueness becomes trivially true. Since most reject the idea that uniqueness is true by definition, there is pressure on defenders of uniqueness to avoid responding to counterexamples by insisting that the agents in question have new evidence.

Given these examples of epistemic supererogation, a defense of (2.2) is relatively straightforward. The idea behind (2.2) is that rationality is a satisficing, rather than a maximizing norm. ${ }^{27}$ The agents in both cases are perfectly rational in having certain beliefs, but their situation is such that there are other beliefs, inconsistent with the first set, that 'go above and beyond' what rationality requires. If there is more than one rational belief-attitude a single agent can have, given her evidence, then IaBP follows.

\section{Doubt}

My second argument for IaBP involves doubt, as follows:

3.1 There are cases where one rationally believes that $p$, comes to doubt that $p$ without a change in one's evidence, and thus rationally comes to withhold belief that $\mathrm{p}$.

3.2 If one can rationally believe and rationally withhold without a change in one's evidence, IaBP is true.

\subsection{IaBP is true.}

Of the two premises in this argument, (3.1) is much more controversial. In this section, I defend (3.1) by focusing on two classes of cases: cases of pragmatic encroachment on rational belief, and cases where one is primed and/or a possibility is made salient, without a change in stakes. I will argue that, in these cases, doubt can cause one to go from rationally believing to rationally withholding without a change in evidence. This view meshes well with recent accounts of doubt, on which S's doubting $\mathrm{p}$ is importantly connected to the salience of the possibility of not-p for $\mathrm{S}^{28}$

The general structure of these cases is as follows: at T1, S believes $\mathrm{p}$ and $\mathrm{S}$ believes (or knows) that not-p is possible, but this possibility is not salient. Then, at T2, something happens (e.g. priming, a change in stakes) that makes $S$ begin to take the possibility of not-p seriously, such that $S$ comes to doubt $p$. If the possibility of not-p is salient enough, $\mathrm{S}$ can come to rationally withhold belief that $\mathrm{p}$ at T3. $\mathrm{S}$ does not gain or lose any evidence from T1-T3. ${ }^{29}$ These cases will most likely be ones where, at T1, S is not extremely confident in or firmly committed to her belief.

\subsubsection{Pragmatic encroachment}

One class of examples that support (3.1) are pragmatic encroachment cases. Generally, pragmatic encroachment is the thesis that the practical has certain effects in the epistemic domain. ${ }^{30}$ Early in the pragmatic encroachment debate, most people were

\footnotetext{
${ }^{26}$ See Kopec and Titelbaum (2016), Ballantyne and Coffman (2011).

${ }^{27}$ Thanks to Brian Cutter. See Christensen (2016), Schoenfield (Forthcoming).

${ }^{28}$ See Howard-Snyder (2013), Moon (2017), Jackson (Forthcoming b).

${ }^{29}$ Thanks to Amy Flowerree.

${ }^{30}$ For an overview of the pragmatic encroachment debate, see Kim (2017).
} 
focusing on whether the practical can affect knowledge, ${ }^{31}$ i.e. whether one's practical circumstances can affect whether one knows some proposition. Lately, however, many have focused on whether the practical can affect epistemic justification or epistemic rationality. ${ }^{32}$ Here, my focus is on the latter kind of pragmatic encroachment. Thus, for our purposes, pragmatic encroachment is the view that what it is epistemically rational for an agent to believe can vary based on their practical circumstances. Specifically, these cases will be ones in which S's belief that $\mathrm{p}$ is rational when the stakes are low, but is no longer rational when the stakes become high.

For example, suppose I have good evidence that the sandwich in my fridge is made with almond butter - for instance, my roommate made it, and my roommate almost always makes almond butter sandwiches. It seems rational for me to believe there is an almond butter sandwich in the fridge, and assert this to you if you are hungry and ask for a snack. However, consider a second version on the case in which my evidence is the same, i.e. I again know my roommate made the sandwich and my roommate almost always makes almond butter sandwiches. However, suppose I also know that you are deathly allergic to peanut butter and that there is some small chance my roommate made it with peanut butter instead of almond butter. Even though I haven't gained or lost any evidence that bears on whether the sandwich is in fact made with almond butter, it seems like I should withhold belief on whether it is an almond butter sandwich. ${ }^{33}$ Examples like these seem to generalize: if pragmatic encroachment occurs, a change in practical circumstances without a change in evidence that bears on whether $\mathrm{p}$ can affect whether it is rational for one to believe $\mathrm{p}$.

One might object that in many of these cases, there is a change in my total evidence - namely, I become aware that my practical circumstances have changed. ${ }^{34}$ In response, it is worth noting that the evidence that is ultimately relevant for the permissivism/ uniqueness debate is the subset of the agent's evidence that bears on whether p. If A is rational to hold doxastic attitude $d$ toward $p$ at $t$, and then at $t 2 A$ 's evidence changes, but none of the changes are relevant to whether $\mathrm{p}$ (including higher-order evidence bearing on whether A ought to believe $\mathrm{p}$ ), it seems absurd for the impermissivist to maintain that, in virtue of that change, it is rational for A to hold something other than $d$ toward $p$ at $t 2$. Why would changes in one's evidence, irrelevant to $p$, change what attitude one is permitted to hold? This is not only implausible but opposed to the spirit of uniqueness. Thus, appealing to irrelevant changes in one's evidence, e.g. one's beliefs about one's practical circumstances, to save uniqueness is not a helpful strategy for an impermissivist to pursue. ${ }^{35}$

Thus, if there is pragmatic encroachment on rational belief, one can rationally believe and rationally withhold without a relevant evidential change.

\subsubsection{Priming and salience}

My argument in this section does not stand or fall on whether the pragmatic encroachment thesis is true. There are other cases of doubt that support (3.1): cases where one takes time to think through alternative possibilities, one is primed with a particular possibility, or these possibilities are made salient for some other reason.

\footnotetext{
${ }^{31}$ See Hawthorne (2003), Stanley (2005).

${ }^{32}$ See Fantl and McGrath (2002, 2010), Schroeder (2012), Ross and Schroeder (2014), along with most of those in the moral encroachment literature. I will not distinguish between epistemic justification and epistemic rationality for the purposes of this paper.

${ }^{33}$ This example is from Jackson (2019).

${ }^{34}$ Thanks to Blake Roeber.

${ }^{35}$ See Hedden (2015b) and Rubin (2015) for discussion.
} 
For example, one might believe $\mathrm{p}$, then, due to doubt, come to withhold with respect to $\mathrm{p}$ upon being primed with a skeptical hypothesis. You believe your car is in the parking lot outside right now, but if I were to prime you with the fact that it could have been stolen or towed, point out that you really don't know that it hasn't been, etc., this might cause you to doubt enough that withholding is rational for you. Alternatively, consider a student in your Introduction to Philosophy class, who has seen The Matrix, and comes to class believing, non-occurrently, that it is possible that all her external-world beliefs are false. Nonetheless, before coming into class, she rationally believes she has hands. She may sit through class without gaining any new evidence, but at the end of class, rationally withhold belief that she has hands, as she has been effectively primed with skepticism by her philosophy professor.

One might worry that the doubt in these cases isn't rational. For example, being primed by skeptical scenarios might make your students doubt as a matter of psychological fact, but it is less clear that their doubt is epistemically justified. ${ }^{36}$ In response, it might help to explicate more fully the cases of doubt I have in mind. Due to the fact we have finite cognitive capacities, we can only consider so many possibilities at once. In many situations, it is perfectly rational to believe something, ruling out or never considering the possibility or error - we do this all the time when we form a belief that $\mathrm{p}$ on less-than-perfect evidence for $\mathrm{p}$. However, once the possibility of error becomes salient, one is faced with the real possibility they could be wrong. Here, withholding belief seems, at the very least, to be a rationally permitted response to one's epistemic situation. And of course, I don't want to argue that withholding belief is always rationally required when one faces the possibility of error; I merely claim that, in some cases, the possibility of error can cause one to rationally withhold. Further, the idea that rational belief is sensitive to the possibilities that are live for an agent is one that finds support in the literature. For instance, Hannes Leitgeb defends the thesis that rational belief is partition-sensitive: what one ought to believe depends on what possibilities are live for that person. ${ }^{37}$ Nonetheless, the connections of this view (and related views) to permissivism have been overlooked.

A second worry is that priming involves a change in evidence. ${ }^{38}$ In some cases of priming, this very well might be the case; for example, if I gave you statistical evidence that cars are stolen out of parking lots much more than you previously thought, or if a student encounters a new argument for skepticism they hadn't considered before. However, I maintain that there are at least some cases of priming that do not involve a change in evidence. Again, due to our finite capacities, one can only occurrently consider so many possibilities at once. Given this, we may ignore possibilities and later then re-consider them, and this need not always involve forming a new modal belief or some other change in evidence. This picture is complemented by one presented by Mark Schroeder (2012), who argues that there are non-evidential but epistemic reasons to move from belief to withholding; these reasons often arise when we are faced with, and want to avoid, the possibility of error. ${ }^{39}$

Finally, I remind the reader of the point made at the end of Section 2: proponents of uniqueness want to be careful insisting that evidence change is cheap or common. The easier it is for one's evidence to change, the more trivial the uniqueness thesis becomes. While this is always a way out for proponents of uniqueness, my aim is to have

\footnotetext{
${ }^{36}$ Thanks to Gregg TenElshof and an anonymous referee.

${ }^{37}$ See Leitgeb $(2014,2015,2017)$. See also Yalcin (2018) and Jackson (Forthcoming $b$ ).

${ }^{38}$ Thanks to Blake Roeber.

${ }^{39}$ While Schroeder's focus is on pragmatic encroachment cases, his model can be easily translated into cases of priming without a change in stakes.
} 
identified some of the most plausible cases where a change in rational belief is possible without a change in evidence.

Thus, (3.1) enjoys support both from pragmatic encroachment and the possible effects of priming. In these cases, new possibilities become salient for the agents in question, and they doubt what they once believed. They go from rationally believing to rationally withholding without a change in evidence. (3.2) straightforwardly follows from the definition of permissivism. If one rationally believes $\mathrm{p}$ on the basis of some evidence, but, as the result of doubt, can rationally withhold with respect to $\mathrm{p}$ on the basis of that same evidence, IaBP follows.

\section{The toggling objection}

I close by considering an objection to IaBP: White's toggling objection. Namely, if a body of evidence permits more than one attitude, then what prevents a rational agent from randomly moving in between the permitted attitudes? ${ }^{40}$ White imagines a scenario in which you have a pill that makes you believe $\mathrm{p}$ and another pill that makes you believe not-p. You know that both belief that $p$ and belief that not-p are permitted by your evidence, so you take the p pill and believe $\mathrm{p}$. Then, you decide you want to believe not-p instead, so you take the not-p pill. White (2013: 317) notes, "And of course I can switch back again. Each time I toggle my beliefs in this manner I am relieved to find that my resulting opinion is true. The absurdity of this should make us wonder whether permissive cases are possible." This sort of random belief toggling seems irrational, but it is unclear that the permissivist has the resources to explain why.

Permissivists have provided a number of responses to White in the literature, but it is worth addressing the objection here for at least two reasons. First, many of the responses so far have been made on behalf of IeP (Interpersonal Permissivism), but don't apply to IaP (Intrapersonal Permissivism). For instance, defenders of IeP respond to White by appealing to facts about me that aren't part of my evidence, but nonetheless, together with my evidence, uniquely determine what I should believe. For example, Schoenfield (2014) argues that epistemic standards fall into this category. On Schoenfield's picture, given my evidence and my epistemic standards, only one attitude toward $\mathrm{p}$ is rational for me, so toggling is not permitted. Her picture is nonetheless permissive because, even if you share my evidence, you might have a different epistemic standard, and thus a different attitude toward $\mathrm{p}$ is rational for you. Thus, there is more than one rational attitude towards a proposition, given a body of evidence. Kelly (2013) argues for a similar view, but instead of epistemic standards, he appeals to the different ways that agents might weigh the Jamesian epistemic goals of pursuing truth and avoiding error. On either picture, toggling is impermissible, because what one ought to believe is fully determined by the conjunction of one's evidence and these extra-evidential epistemic facts about them. This response to the toggling worry, while convincing, only establishes permissivism on an interpersonal level, and is thus unavailable for the defender of IaP.

The second reason I mention White's objection is because the strand of IaP that I defend in this paper offers a unique response to the toggling worry. This response has gone largely unnoticed in the permissivism literature; this might partially explain the relative unpopularity of IaP. However, toggling isn't a problem, at least for certain versions of IaP.

Recall that, according to uniqueness, the only thing that determines what attitude a rational agent ought to hold is her evidence; there is a function, whose only input is an agent A's evidence, that spits out a single rational belief-attitude for A. However, there is

\footnotetext{
${ }^{40}$ White (2013: 318). Hedden (2015b: 149) also advances a version of this objection.
} 
a way of denying this, consistent with IaBP, that does not entail the permissibility of toggling.

Note that being a permissivist does not commit one to the idea that rationality is underdetermined in general; permissivism merely commits one to the idea that rationality is (sometimes) underdetermined by evidence alone. ${ }^{41}$ This is why the interpersonal view described above is a permissive one; even if rational belief is always completely determinate for each individual, it is a function of more than their evidence, so two agents can share evidence but rationally disagree.

In this paper, I've gone beyond this suggestion and argued that varying additional background factors cannot change what it is rational for a single agent to believe. On my view, there are plausible inputs for an agent's rational belief function other than evidence. These include those mentioned in the above arguments: the hypotheses that are live for an agent, the amount of time one takes to think about one's evidence, the insights one has, what is at stake, and what is salient. This brings out a connection between the two positive arguments in this paper. ${ }^{42}$ Both arguments are for strands of what you might call diachronic permissivism, in which, over time, non-evidential changes in one's epistemic situation can change what it is rational for a single agent to believe. I've focused primarily on changes in the hypotheses or possibilities that are live for an agent.

Further, it is worth noting that the rational belief function might have additional inputs that go beyond those mentioned in this paper's positive arguments. For example, an agent might be committed to a viewpoint for prudential reasons: she might hold a belief because it uniquely has certain benefits (e.g. a Pascalian reason for believing in God, having a belief makes her happy, etc.), even if her evidence permits other doxastic attitudes. One might also hold a belief because it has virtues that other beliefs don't have, like simplicity, explanatory power, or unification, ${ }^{43}$ or for other non-evidential epistemic reasons. $^{44}$

Returning to White's objection, then, we can clarify which specifications of IaP are vulnerable to toggling. His objection seems to apply to something like the following:

Synchronic IaBP: there are evidential situations in which a particular time-slice of an agent can rationally adopt more than one belief-attitude toward a proposition. ${ }^{45}$

In other words, Synchronic IaBP entails that, at a time, rational belief is completely underdetermined: by evidence, epistemic standards, or anything else. More than one doxastic attitude is "live" for an agent at a particular time, and the agent can pick either one without compromising rationality.

Yet we can embrace IaBP without committing to anything as strong as Synchronic IaBP; we can instead opt for a diachronic version of IaBP, such as the following:

Diachronic IaBP: there are evidential situations in which two (or more) different time-slices of an agent can rationally adopt more than one belief-attitude toward a proposition. $^{46}$

\footnotetext{
${ }^{41}$ Thanks to Maria Lasonen-Aarnio. For more on this point, and how different varieties of permissivism interact with evidentialism, see Jackson and Turnbull (Forthcoming).

${ }^{42}$ Thanks to an anonymous referee for suggesting I explore these connections.

${ }^{43}$ See Nolan (2014).

${ }^{44}$ See Schroeder (2012).

${ }^{45}$ Thanks to Samuel Dishaw. See Podgorski (2016) and Roeber (Forthcoming).

${ }^{46}$ This definition is complicated by the fact that changes in one's total evidence are quite easy to come by; we are continually perceiving new things, losing old memories, etc. (Thanks to an anonymous referee). However, what is ultimately relevant for the permissivism/uniqueness debate is one's evidence that bears on whether $\mathrm{p}$, where $\mathrm{p}$ is the object of the possibly permitted attitude. A more precise version of diachronic
} 
On this view, no two doxastic attitudes are ever live for an agent at the same time. Rather, what is rational for one to believe changes as non-evidential aspects of their epistemic situation change. Diachronic IaBP is immune to White's toggling objection, because one cannot move between attitudes randomly, but can only do so as particular facts about their epistemic situation change. Thus, White and others seem to be attacking a very extreme version of permissivism (i.e. Synchronic IaBP). However, there are versions of IaBP (which is itself an extreme view) that are moderate enough to escape White's objections. ${ }^{47}$

Here, I am satisfied to defend Diachronic IaBP. I won't take a stand on whether Synchronic IaBP is true, although I am not convinced that the toggling objection is fatal for even Synchronic IaBP. ${ }^{48}$ Ultimately, whether Synchronic IaBP is true is a question I will leave open for future research, but I hope that carving up the various points in logical space allows future debates to proceed more neatly.

\section{Conclusion}

I have argued for Intrapersonal Belief Permissivism, the view that a single agent can rationally hold more than one belief-attitude toward a proposition, given a body of evidence. First, I have argued that cases of epistemic supererogation entail IaBP. Second, I have argued that a plausible account of doubt supports IaBP. Finally, I've shown how this picture gives us a response to the toggling objection on behalf of the intrapersonal permissivist.

On one hand, these arguments establish a relatively strong version of permissivism that has not been widely accepted: Intrapersonal Belief Permissivism. On the other hand, because I am only arguing for a diachronic strand of permissivism, my arguments are consistent with a view that, in some sense, is in the spirit of uniqueness: that rational belief is determined by the whole of one's epistemic situation. Nonetheless, I maintain that evidence is not the only input into the rational belief function; other background factors, such as the hypotheses that are live for an agent, the amount of time one takes to think about one's evidence, the insights one has, what is at stake, and what is salient are plausible additional inputs. ${ }^{49}$ This concludes my defense of IaBP. ${ }^{50}$

IaBP would focus on changes in one's evidence that bear on whether p. For instance: one's evidence that bears on whether $\mathrm{p}$ can remain constant, but two (or more) different time-slices of an agent can rationally adopt more than one belief-attitude toward p. I discuss this more in section 3.3.1.

${ }^{47}$ Thanks to Joey Pollock.

${ }^{48}$ There is a good reason to think that the act of toggling itself is irrational. First, it seems prudentially irrational. If one frequently takes belief-inducing pills that alter one's beliefs at random, this makes decision making, goal setting, and life planning very difficult. There is also good reason to think that the fact that both attitudes are permitted for me at a time does not entail that toggling is epistemically permitted, either. Suppose I wake up in the morning and pour myself a bowl of cereal, and grab a spoon from the silverware drawer to eat it. It is permissible for me to eat my cereal with any of the spoons in the drawer; in fact, there is no reason to pick one spoon over another. However, this does not entail that "toggling" between spoons is permissible for me - I have already picked a spoon and once I have picked one, there is no sense in switching to another. In the same way, simply because several attitudes are epistemically permitted for me does not entail that it can be rational for me to switch whenever I'd like. Thanks to Blake Roeber.

Finally, if one is unconvinced by the above reasoning, I think a third plausible way to defend Synchronic IaBP is to simply bite the bullet, and maintain that in some (maybe rare) cases, toggling is epistemically permitted. White says that a toggling situation is "absurd" but beyond that, doesn't give much argument that toggling is irrational. Without a further story here, it's hard to see why toggling is so epistemically bad.

${ }^{49}$ Thanks to Joey Pollock.

${ }^{50}$ Thanks to Scott Stapleford, Blake Roeber, Ru Ye, Lizzie Fricker, Joey Pollock, Mike Titelbaum, Max Hayward, Adam Pesler, Nathan King, audiences at the 2018 Central APA, 2017 Edinburgh Graduate 
Author ORCIDs. (D) Elizabeth Jackson, 0000-0002-6234-4488

\section{References}

Ballantyne N. and Coffman E.J. (2011). 'Uniqueness, Evidence, and Rationality.' Philosophers' Imprint 11, $1-13$.

Ballantyne N. and Coffman E.J. (2012). 'Conciliationism and Uniqueness.' Australasian Journal of Philosophy 90, 657-70.

Berker S. (2018). 'A Combinatorial Argument against Practical Reasons for Belief.' Analytic Philosophy 59, 427-70.

Bernstein M. (1986). 'Moral and Epistemic Saints.' Metaphilosophy 17(2/3), 102-8.

Brueckner A. and Bundy A. (2012). 'On 'Epistemic Permissiveness'.' Synthese 188, 165-77.

Carter J.A. (2017). 'Virtuous Insightfulness.' Episteme 14(4), 539-54.

Christensen D. (2007). 'Epistemology of Disagreement: The Good News.' Philosophical Review 116, 187-217.

Christensen D. (2016). 'Conciliation, Uniqueness and Rational Toxicity.' Noûs 50(3), 584-603.

Daoust M.K. (2017). 'Epistemic Uniqueness and the Practical Relevance of Epistemic Practices.' Philosophia 45(4), 1-13.

Dahlback M. (Forthcoming). 'Infinitely Permissive.' Erkenntnis. https://www.academia.edu/20402399/ Infinitely_Permissive.

Decker J. (2012). 'Disagreement, Evidence, and Agnosticism.' Synthese 187, 753-83.

Dogramaci S. and Horowitz S. (2016). 'An Argument for Uniqueness about Evidential Support.' Philosophical Issues 26(1), 130-47.

Douven I. (2009). 'Uniqueness Revisited.' American Philosophical Quarterly 46, 347-61.

Drake J. (2017). 'Doxastic Permissiveness and the Promise of Truth.' Synthese 194, 4897-912.

Fantl J. and McGrath M. (2002). 'Evidence, Pragmatics, and Justification.' Philosophical Review 111(1), 67-94.

Fantl J. and McGrath M. (2010). Knowledge in an Uncertain World. Oxford: Oxford University Press.

Feldman R. (2000). 'The Ethics of Belief.' Philosophy and Phenomenological Research 60(3), 667-95.

Feldman R. (2006). 'Epistemological Puzzles about Disagreement.' In S. Hetherington (ed.), Epistemology Futures, pp. 216-36. Oxford: Oxford University Press.

Feldman R. (2007). 'Reasonable Religious Disagreement.' In L. Antony (ed.), Philosophers Without God, pp. 197-214. Oxford: Oxford University Press.

Greco D. and Hedden B. (2016). 'Uniqueness and Metaepistemology.' Journal of Philosophy 113(8), 365-95.

Hawthorne J. (2003). Knowledge and Lotteries. Oxford: Oxford University Press.

Hedberg T. (2014). 'Epistemic Supererogation and its Implications.' Synthese 191(15), 3621-37.

Hedden B. (2015a). 'Time-Slice Rationality.' Mind 124, 449-91.

Hedden B. (2015b). Reasons Without Persons: Rationality, Identity, and Time. Oxford: Oxford University Press.

Howard-Snyder D. (2013). 'Propositional Faith: What it is and What it is Not.' American Philosophical Quarterly 50(4), 357-72.

Horowitz S. (2014). 'Immoderately Rational.' Philosophical Studies 167, 41-56.

Horowitz S. (2019). 'The Truth Problem for Permissivism.' Journal of Philosophy 116(5), 237-62.

Jackson E. (Forthcoming a). 'Belief and Credence: Why the Attitude-Type Matters.' Philosophical Studies. https://doi.org/10.1007/s11098-018-1136-1.

Jackson E. (Forthcoming b). 'Belief, Credence, and Evidence.' Synthese. https://doi.org/10.1007/s11229018-01965-1.

Jackson E. (2019). 'How Belief-Credence Dualism Explains Away Pragmatic Encroachment.' Philosophical Quarterly 69(276), 511-33. https://doi.org/10.1093/pq/pqz006.

Jackson E. and Turnbull M. (Forthcoming). 'Permissivism, Underdetermination, and Evidence.' In C. Littlejohn and M. Lasonen-Aarnio (eds), The Routledge Handbook for the Philosophy of Evidence. New York, NY: Routledge.

Jung J. (2016). 'Conservatism and Uniqueness.' Philosophical Studies 173(8), 2233-48.

Jung J. (2017). 'Steadfastness, Deference, and Permissive Rationality.' Synthese 194, 5093-112.

Epistemology Conference, 2017 Pacific Division Meeting of the Society for Christian Philosophers, the Notre Dame Graduate Student Colloquium, the 2016 Iowa Philosophical Society, and an anonymous referee at this journal for helpful comments on earlier versions of this paper. 
Kelly T. (2002). 'The Rationality of Belief and Some Other Propositional Attitudes.' Philosophical Studies 110(2), 163-96.

Kelly T. (2013). 'Evidence can be Permissive.' In M. Steup, J. Turri and E. Sosa (eds), Contemporary Debates in Epistemology, pp. 298-311. Hoboken, NJ: John Wiley \& Sons.

Kim B. (2017). 'Pragmatic Encroachment in Epistemology.' Philosophy Compass 2,1-14.

Kopec M. (2015). 'A Counterexample to the Uniqueness Thesis.' Philosophia 43, 403-9.

Kopec M. and Titelbaum M. (2016). 'The Uniqueness Thesis.' Philosophy Compass 11(4), 189-200.

Lee M. (2013). 'Conciliationism without Uniqueness.' Grazer Philosophische Studien 88, 161-88.

Leitgeb H. (2014). 'The Stability Theory of Belief.' In Philosophical Review 123(2), 131-71.

Leitgeb H. (2015). 'The Humean Thesis on Belief.' Proceedings of the Aristotelian Society of Philosophy 89(1), 143-85.

Leitgeb H. (2017). The Stability of Belief. How Rational Belief Coheres with Probability. Oxford: Oxford University Press.

Levinstein B. (2015). 'Permissive Rationality and Sensitivity.' Philosophy and Phenomenological Research 94 (2), 342-70.

Li H. (2019). 'How Supererogation Can Save Intrapersonal Permissivism.' American Philosophical Quarterly 56(2), 171-86.

Matheson J. (2011). 'The Case for Rational Uniqueness.' Logos \& Episteme 2, 359-73.

Meacham C. (2014). 'Impermissive Bayesianism.' Erkenntnis 79, 1185-217.

Meacham C. (2019). 'Deference and Uniqueness.' Philosophical Studies 176(3), 709-32.

McElwee B. (2016). 'Supererogation Across Normative Domains.' Australasian Journal of Philosophy 95(3), 505-16.

Moon A. 2017. 'The Nature of Doubt and a New Puzzle About Belief, Doubt, and Confidence.' Synthese 195(4), 1827-48.

Nolan D. (2014). 'Dangers of Pragmatic Virtue.' Inquiry 57(5-6), 623-44.

Peels R and Booth A. (2014). 'Why Responsible Belief Is Permissible Belief.' Analytic Philosophy 55, 75-88.

Podgorski A. (2016). 'Dynamic Permissivism.' Philosophical Studies 173, 1923-39.

Raleigh T. (2015). 'An Argument for Permissivism from Safespots.' In W. van der Hoek (ed.), Logic, Rationality, and Interaction, pp. 308-15. Berlin: Springer-Verlag.

Raleigh T. (2017). 'Another Argument Against Uniqueness.' Philosophical Quarterly 67(267), 327-46.

Roche W. and Sober E. (2013). 'Explanatoriness is Evidentially Irrelevant, or Inference to the Best Explanation meets Bayesian Confirmation Theory.' Analysis 73(4), 659-68.

Roeber B. (Forthcoming). 'Permissive Situations and Direct Doxastic Control.' Philosophy and Phenomenological Research. https://doi.org/10.1111/phpr.12594.

Rosa L. (2012). 'Justification and the Uniqueness Thesis.' Logos \& Episteme 3, 571-7.

Rosen G. (2001). 'Nominalism, Naturalism, Epistemic Relativism.' Philosophical Perspectives 15, 69-91.

Ross J. and Schroeder M. (2014). 'Belief, Credence, and Pragmatic Encroachment.' Philosophy and Phenomenological Research 88(2), 259-88.

Rubin K. (2015). 'Total Pragmatic Encroachment and Epistemic Permissiveness.' Pacific Philosophical Quarterly 96, 12-38.

Schoenfield M. (2014). 'Permission to Believe: Why Permissivism Is True and What It Tells Us About Irrelevant Influences on Belief.' Nô̂s 48, 193-218.

Schoenfield M. (Forthcoming). 'Permissivism and the Value of Rationality: A Challenge to the Uniqueness Thesis.' Philosophy and Phenomenological Research. https://doi.org/10.1111/phpr.12490.

Schroeder M. (2012). 'Stakes, Withholding, and Pragmatic Encroachment on Knowledge.' Philosophical Studies 160(2), 265-85.

Schultheis G. (2018). 'Living on the Edge: Against Epistemic Permissivism.' Mind 127(504), 863-79.

Sharadin N. (2015). 'A Partial Defense of Permissivism.' Ratio 30(1), 57-71.

Simpson R.M. (2017). 'Permissivism and the Arbitrariness Objection.' Episteme 14, 519-38.

Stanley J. (2005). Knowledge and Practical Interests. Oxford: Oxford University Press.

Stapleford S. (2013). 'Imperfect Epistemic Duties and the Justificational Fecundity of Evidence.' Synthese 190(18), 4065-75.

Stapleford S. (2015). 'Why There May be Epistemic Duties.' Dialogue 54(1), 63-89.

Stapleford S. (Forthcoming). 'Intraspecies Impermissivism.' Episteme. https://doi.org/10.1017/epi.2018.14.

Thorstad D. (Forthcoming). 'Permissive Metaepistemology.' Mind. https://doi.org/10.1093/mind/fzy044.

Tidman P. (1996). 'Critical Reflection: An Alleged Epistemic Duty.' Analysis 56(4), 268-76. 
Titelbaum M. (2010). 'Not Enough There There: Evidence, Reasons, and Language Independence.' Philosophical Perspectives 24, 477-528.

Titelbaum M.G. and Kopec M. (2019). 'When Rational Reasoners Reason Differently.' In M. Balcerak-Jackson and B. Balcerak-Jackson (eds), Reasoning: Essays on Theoretical and Practical Thinking, pp. 205-31. Oxford: Oxford University Press.

Weisberg J. (Forthcoming). 'Could've Thought Otherwise.' Philosopher's Imprint. https://jonathanweisberg. org/pdf/CTO.pdf.

White R. (2005). 'Epistemic Permissiveness.' Philosophical Perspectives 19, 445-59.

White R. (2007). 'Epistemic Subjectivism.' Episteme 4, 115-29.

White R. (2013). 'Evidence Cannot Be Permissive.' In M. Steup, J. Turri and E. Sosa (eds), Contemporary Debates in Epistemology, pp. 312-23. Hoboken, NJ: John Wiley \& Sons.

Williamson J. (2004). Bayesian Nets and Causality: Philosophical and Computational Foundations. Oxford: Oxford University Press.

Williamson J. (2010). In Defense of Objective Bayesianism. Oxford: Oxford University Press.

Williamson T. (2000). Knowledge and its Limits. Oxford: Oxford University Press.

Williard-Kyle C. (2017). 'Do Great Minds Really Think Alike?' Synthese 194, 989-1026.

Yalcin S. (2018). 'Belief as Question-Sensitive.' Philosophy and Phenomenological Research 97(1), 23-47.

Elizabeth Jackson is a Research Fellow at Australian National University, and an Assistant Professor at Ryerson University (starting Fall 2020). Her research is primarily in epistemology, much of it focusing on issues at the intersection of formal and traditional epistemology. She completed her $\mathrm{PhD}$ in Philosophy at the University of Notre Dame in 2019.

Cite this article: Jackson E (2021). A Defense of Intrapersonal Belief Permissivism. Episteme 18, 313-327. https://doi.org/10.1017/epi.2019.19 